\title{
ENTRE SABER E OLHAR: NOTAS SOBRE A EXPERIÊNCIA DA VISUALIDADE E O DESENHO DE AMADOR PEREZ
}

\author{
Ludmila Vargas Almendra ${ }^{1}$
}

"Nunca se saberá olhar um quadro" (Didi-Huberman, 2013: 297). Com essa colocação, Georges Didi-Huberman assinala os limites conceituais e os enquadramentos disciplinares que abordam a arte como objeto de conhecimento, chamando a atenção para a necessária revisão dos fins da história da arte que vêm se construindo, desde Giorgio Vasari. A trajetória de pensamento de Didi-Huberman se endereça a interrogá-los, expondo as fragilidades que residem na aparente suficiência e exatidão que proclamam, ainda que se reconheça e afirme, no mundo acadêmico, a contribuição da disciplina em suas abordagens biográfica, iconográfica, social, semiológica ou formalista. Trata-se de um apelo das próprias imagens, que não cessam de apresentar sua dimensão inapreensível e ininteligível quando lhes é permitido mostrarem-se sem que, antes, sejam encerradas em redes de teorizações e categorias de pensamento. Mostrar-se: fazer-se ver, apresentar-se, dar-se a conhecer.

Desse modo, acompanhando a crítica ao discurso que enreda seu objeto, o autor recoloca o olhar como problema central na compreensão da obra artística, ou ainda, da imagem. A obra de arte visual, ao ser encarada, revela-se como acontecimento e solicita um trabalho visual a ser experimentado e realizado. Nele, aquilo que escapa ao saber não deixa de impor sua presença ao olhar. Então, uma efetiva investigação do fato artístico implica ir de encontro a esta presença e ao modo como nos afeta, questão que motivou esse artigo.

Essas reflexões, que serão desenvolvidas a seguir, encontram eco na poética de Amador Perez (1952). Os desenhos do artista reinterpretam imagens extraídas da cultura visual e artística e convidam a encarar a visualidade como experiência, espécie de iniciação e abertura ao mundo percebido (Almendra ${ }^{2}, 2013$ ).

\section{A experiência visual e o mundo percebido}

A obra de arte visual se mostra, pertence ao domínio da visualidade antes de ser apreendida pelo pensamento. Essa preocupação corresponde à crítica presente nas diversas

\footnotetext{
${ }^{1}$ Centro Federal de Educação Tecnológica Celso Suckow da Fonseca, Brasil.

${ }^{2} \mathrm{O}$ presente artigo tem origem no estudo desenvolvido na tese Experiência do desenho: um estudo sobre poéticas desenhantes e Amador Perez, sob a orientação de Angela Ancora da Luz.
} 
correntes fenomenológicas que questionam os modelos de pensamento científico que divorciam seus objetos da vivência humana que os institui e significa. Conserva-se, dentre os diferentes atores da fenomenologia, durante o século XX, o interesse pela subjetividade e a insistência de que o pensamento científico precisa reconhecer os limites de alcance de suas conclusões e recolocar-se na relação originária estabelecida entre o sujeito e o mundo. Tal retorno à origem, para Maurice Merleau-Ponty, é viabilizado pelo acesso ao mundo percebido, mundo que se oferece aos sentidos, de onde brotam as formas de consciência, de onde se pode "trazer à consciência reflexiva a integralidade de nosso ser-no-mundo envolvida em uma situação" (Matthews, 2011: 31).

Segundo a filosofia merleau-pontiana, a arte exerce essa forma de saber em cumplicidade com o aparecer do mundo, como abertura às interrogações ${ }^{3}$, capaz de interromper momentaneamente o pensamento sobre as coisas e apresentá-las à percepção. $\mathrm{O}$ exercício da arte seria, então, análogo ao da fenomenologia, cuja tarefa é

retornar a este mundo antes do conhecimento cujo conhecimento fala sempre, e com respeito ao qual toda determinação científica é abstrata, representativa e dependente, como a geografia com relação à paisagem onde aprendemos primeiramente o que é uma floresta, um campo, um rio. (Merleau-Ponty, 1971: 7)

É importante salientar que a reabilitação do mundo percebido, pré-reflexivo, não implica em renúncia às estruturas reflexivas pelas quais o mundo cultural é representado, mas na frequentação do solo que as sustenta, para melhor compreendê-lo. Assim, identificado com o mundo dos fenômenos, o fazer artístico ensina que não se pode distinguir as coisas do modo como aparecem. Em presença das coisas percebidas, experimenta-se uma espécie de correspondência entre qualidades e aspectos, correlata à correspondência dos próprios sentidos. Por isso é possível referir-se a um limão, vendo sua acidez, saboreando sua cor, sorvendo o frescor de sua forma. A coisa não é percebida como adição de seus aspectos ou somatório de características, a partir de uma síntese intelectual, mas pela expressão de uns aspectos através dos outros (Merleau-Ponty, 2004ㄹ 22-23) ${ }^{4}$. Tal entrecruzamento experimentado no mundo percebido, em geral é esquecido sob os acúmulos da vida cultural e das teorizações. O mistério que funda essa percepção do mundo, que anima e amalgama todos

\footnotetext{
${ }^{3}$ Ao tratar a relação dos artistas com a construção de saberes sobre o mundo, Georges Didi-Huberman constata: "Pelo menos, deslocando os pontos de vista, revirando os espaços, inventando novas relações, novos contatos, sabem encarnar as questões mais essenciais, o que é bem melhor que acreditar responder a elas" (2009: 37)

${ }^{4}$ Merleau-Ponty desenvolve a reflexão, retomando-a de Sartre, em L'être et le Néant (O Ser e o Nada). Ver Merleu-Ponty. Conversas-1948. São Paulo: Martins Fontes, 2004.
} 
os aspectos que se afetam mutuamente no ser, não deve ser entendido como obstáculo ao conhecimento, mas a sua fonte primeira, conforme salienta Merleau-Ponty.

Assim, a tarefa fenomenológica de elucidar as relações vividas e afetivas entre o homem e o mundo, descrevendo seus modos de aparecer, encontra certo parentesco na arte, exercício por excelência desse esforço de elucidação. Interessa, portanto, redimensionar a luz da experiência perceptiva na compreensão das manifestações artísticas e culturas visuais. Contudo, a realidade percebida se apresenta como um paradoxo, posto que nunca é apreensível completamente, de um único ponto de vista, como se fosse observada por um sujeito em geral. É realidade que se mostra sempre inacabada, atrelada à singularidade de cada visada, revelando-se multifacetada (Chauí, 2002: 199).

Portanto, a experiência artística atua no inacabamento desse mundo, através do qual há sempre aparecimentos, e que "não é apenas o conjunto de coisas naturais, é também os quadros, as músicas, os livros" (Merleau-Ponty, 2004a: 65). Por conseguinte, Merleau-Ponty recorre à prática dos pintores, músicos ou escritores, indo de encontro a formas de saber que distinguem o sujeito percipiente do sujeito transcendental, concebido fora da experiência. Atenta para os momentos em que a criação artística ultrapassa os sedimentos do conhecimento instituído, distanciando-se tanto do objetivismo científico quanto da subjetividade filosófica, para alcançar o fundo onde se originam o mundo da visão, do som e da fala. Observa que os artistas, em suas atividades, abrem a fenda pela qual a experiência da percepção que sustenta o mundo cultural se exibe, trazendo o visível pela pintura, o audível pela música, o dizível pela fala ou pela escrita. $\mathrm{O}$ filósofo refere-se à pintura como aquela que “eleva à sua máxima potência um delírio que é a própria visão" (2004b, p.26). Sendo assim, quando se trata de potencializar o visível, a arte visual, em seu amplo espectro de manifestações, é capaz de recorrer ao mundo perceptivo, onde sujeito percipiente e vidente encontra-se atrelado ao perceptível e visual. Entende-se, então, que o trabalho visual do artista se realiza nessa reciprocidade.

De forma análoga, Georges Didi-Huberman recorre à literatura, à dança, à arte visual, encontrando situações exemplares de uma fenomenologia da percepção capaz de "reapresentar e inverter velhíssimas proposições metafísicas ou mesmo místicas" sobre o mundo (1998, p.30). Contudo, chama a atenção para o fato de que a aparição do mundo ou abertura ao percebido pela modalidade do visível pode ser afetada pelas mediações da tautologia e da crença. O primeiro discurso fixa-se no objeto, na evidência da visibilidade, e apenas no que é visto enquanto se vê, ignorando o não-visível que lhe dá suporte. O segundo 
discurso crê em sua própria vidência, como construção instituída que abarca cada coisa conforme seu modo de ver. Um encarcera o visível nos atributos do objeto, na figuração das coisas; o outro encobre a visualidade das coisas com modelos construídos pelo sujeito. Em seus exercícios polarizados e excludentes, ambos os discursos evitam o esvaziamento que se deve enfrentar quando o mundo se abre ao percebido, receosos de se perderem nessa travessia em que sujeito e objeto vão de encontro um ao outro, na experiência da visualidade. Para Didi-Huberman, tautologia e crença exprimem, então, formas de desvio, de fuga da modalidade do visível, que, no entanto,

(...) não é nem particularmente arcaica, nem particularmente moderna, ou modernista, ou seja lá o que for. Essa modalidade atravessa simplesmente a longa história das tentativas práticas e teóricas para dar forma ao paradoxo que a constitui (1998: 34)

Relacionados um ao outro pela visualidade, aquele que vê e o visível emprestam um ao outro as chaves de sua abertura. Olham-se através desse vínculo intencional, onde nenhum significado se enraíza em uma das partes, mas se elabora na reciprocidade do olhar. Olhar, aqui, é ver-se mutuamente, encarar-se, mover-se em direção a algo pela vista.

Atento às relações entre arte e mundo percebido, Merleau-Ponty afirma a existência de uma tradição pictórica, imbricada na da visualidade. Para ele, cada pintor retoma a tradição da percepção. A tradição perceptiva é mais antiga que as tradições culturais e sustenta a história. Cada artista a restaura e alimenta, à medida que aciona o mundo percebido através da experiência visual e artística, e com seu gesto abre uma outra tradição: a da "obra como cultura" (Chauí, 2002: 190) ${ }^{5}$. Ainda que seja construção cultural e histórica, notadamente cultura visual e história da arte visual, a obra artística fia-se no mundo percebido.

Essa questão também aparece em Argan, para quem o ponto nodal do conceito de arte não se dá pela distinção categórica, por tipologias ou critérios relacionados aos meios de que o artista dispõe, mas é orientado pela compreensão de sua situação numa perspectiva histórica, do significado de sua participação numa cultura artística, neste caso visual, mas que pode ser intuído no contato com a obra, que "é sempre qualquer coisa que é dada a perceber" (Argan, G. C. e Fagiolo, M., 1992: 14).

\footnotetext{
5 Merleau-Ponty assinala a necessidade da recolocação do pensamento neste "aí prévio, in locus", de onde ramificam os problemas vividos pelos artistas no mundo da cultura artística. Ver O Olho e o Espírito.
}

Iluminuras, Porto Alegre, v. 15, n. 35, p. 180-197, jan./jul. 2014 
Assentir na intuição desse contato primeiro com a obra de arte consiste, então, em retornar à origem da obra como cultura, ao mundo oferecido aos sentidos, revolvendo o solo do logos estético em que ela se funda, para desvendar pela experiência o seu significado.

\section{O trabalho visual do artista}

A intenção do artista só pode realizar-se no seio do seu trabalho, meta e mola da criação. É assim que um desenhista pode trazer o visível à visibilidade. Da mesma forma, a experiência é necessária. É frequentação do mundo percebido.

O fenômeno originário ou abertura do mundo são para Merleau-Ponty sinônimos de experiência, através da qual são atualizadas significações fundamentais (Pascal, 2010: 27). No desenvolvimento de sua filosofia, o termo percepção, que trata da ligação pré-reflexiva do sujeito com o mundo, vai dando lugar ao termo experiência.

Merleau-Ponty chama de Espírito Selvagem o espírito prático, impulsionado pelo agir, determinado a perseguir o que falta ou acrescenta ao já instituído. É aquele que rompe a carapaça do aparelhamento do pensado, com intuito de reativar, refundar, interrogar as significações. Ao Espírito Selvagem não satisfaz a cultura, o estabelecido, mas interessa o indeterminado que sua força criadora pode determinar o invisível que pode tornar visível, o infigurável a figurar. Movido pelo Espírito Selvagem, o artista vai à origem da cultura, à região brutal chamada pelo filósofo de Ser Bruto, para instituí-la de novo.

O Ser Bruto condensa as modalidades sensíveis que possibilitam o sistema expressivo empregado pelo artista, que penetra e deixa-se penetrar por essa realidade sem rupturas. Nesse terreno de indivisibilidade, latências e transitividade entre os sentidos, não há polarização entre sujeito e objeto, percepção e pensamento, corpo e espírito, natureza e cultura. O Ser Bruto compreende o invisível, o espaço magnético entre as coisas visíveis, "a origem como o aqui e o agora que sustenta, pelo avesso, toda forma de expressão" (Chaui, 2002: 155). Por isso, Merleau-Ponty pode comparar o trabalho do pintor ao do tecelão que trabalha às avessas. Concentrado no avesso, no tramado de modalidades do sensível, o artista manipula a germinação de sentidos. Ao se dedicar ao manejo de matéria bruta de sua tecelagem - traçado, cor, espaço, luminosidade - um artista visual pode trazer à vista a modalidade do visível. Assim, Espírito Selvagem e Ser Bruto aliam-se na ação criadora, pelo trabalho do artista.

“Abramos os olhos para experimentar o que não vemos", convoca George DidiHuberman (1998: 34), chamando a atenção para aquilo que Merleau-Ponty compreende como 
ação do Espírito Selvagem no Ser Bruto. Para Didi-Huberman, esse é o trabalho visual experimentar o que não vemos - a que o sujeito é convocado quando está diante da criação, da obra de arte por fazer ou fruir: experimentar a visualidade em suas profundezas não visíveis, naquilo que ultrapassa a evidência da visão, mas a mobiliza e potencializa. Admitindo-se, então, o mistério que aí se encontra, não cabe explicar a visão, mas experimentá-la, pela iniciação.

Com o exercício da experiência, observa-se o movimento em direção ao exterior, ao fora; e com a iniciação, observa-se o movimento contrário, o vir para dentro, a volta à interioridade ou origem. Logo, "percebida, doravante como nosso modo de ser e de existir no mundo, a experiência será aquilo que ela sempre foi: iniciação aos mistérios do mundo" (Chaui, 2002: 161). Nesse sentido, o corpo do sujeito tem participação privilegiada, na filosofia merleau-pontiana. Nele se cumpre a experiência - abertura para o mundo percebido - como culminância da proximidade e da distância com o mundo, onde interior se abre para o exterior sem sair de si.

\section{O trabalho visual do desenhista na poética de Amador Perez}

A experiência de que se trata pode ser discutida a partir da poética de Amador Perez. A reflexão sobre o tema se enriquece, diante de seus desenhos, sobretudo aqueles que se demonstram como reflexões desenhadas sobre o trabalho visual que ampara a cultura visual e artística $^{6}$. Se a experiência na criação artística consiste, por excelência, na abertura ao percebido, na "iniciação aos mistérios do mundo", a criação em Amador reflete a iniciação aos mistérios do mundo da arte.

A pertinência que o desenho assume na trajetória artística de Amador Perez ${ }^{7}$ pode ser constatada não apenas pela intensa produção de desenhos inserida no corpo de sua obra ao longo de 40 anos. Em Amador Perez, o desenho se tornou não só um meio privilegiado de expressão artística, mas como observou o crítico Frederico Morais (1999), um objeto de amor.

\footnotetext{
${ }^{6}$ Refiro-me aos desenhos desenvolvidos a partir de imagens tomadas de empréstimo do mundo da arte e da cultura visual.

${ }^{7}$ Formado em Projeto Gráfico, pela Universidade federal do Rio de Janeiro (1976), o artista reside e trabalha no Rio de Janeiro. Foi professor da Escola Superior de Desenho Industrial da UERJ. Atualmente, é professor do Departamento de Artes e Design da PUC-RJ. Aos 14 anos, estimulado pelos pais (o pai fazia desenhos de arquitetura), começou a frequentar o curso de desenho de Aloísio Carvão, no Museu de Arte Moderna do Rio de Janeiro. Em 2014, comemora 40 anos de carreira. Informações sobre fortuna crítica e biografia do artista podem ser encontradas no site oficial: http://www.amadorperez.com .
}

Iluminuras, Porto Alegre, v. 15, n. 35, p. 180-197, jan./jul. 2014 
Os escritos de Paul Valéry a respeito do desenho na obra de Edgar Degas (1824-1917) podem iluminar a relação de Amador com seu ofício:

\begin{abstract}
O trabalho, o Desenho tinham se tornado nele uma paixão, uma disciplina, o objeto de uma mística e de uma ética que se bastavam por si mesmas, uma preocupação soberana que abolia todos os outros assuntos, uma oportunidade para problemas perpértuos e precisos que o livrava de quaisquer outras curiosidades. Degas era e queria ser um especialista, em um gênero que pode se alçar a uma espécie de universalidade. (Valéry, 2003: 121)
\end{abstract}

Nesse trecho, a intensa ligação de Degas com o desenho é assinalada. Mas a que problemas perpétuos e precisos se refere Valéry? A palavra desenho, grafada com inicial maiúscula, pode ser tomada como sinônimo de trabalho que exige dedicação do artista ao domínio da visualidade, uma visualidade trabalhada na prática desenhista, pela qual se colocam problemas precisamente concernentes à universalidade do visual e aos meios expressivos e técnicas de que se faz uso ao desenhar. É disso que fala Vaéry, é isso que o desenho faz oportuno?

Ao observar com proximidade a experiência desenhista, surpreende ver que o desenho mostra algo que, antes, sem ele, não era visto. Uma consciência singular emerge dessa experiência. "As coisas nos olham. O mundo visível é um excitante perpétuo: tudo desperta ou alimenta o instinto de se apropriar da figura ou do modelado da coisa que o olhar constrói." (Valéry, 2003: 125)

O desenho pode ser compreendido como esse modo de construção pelo olhar, guiado pela relação entre o olho do desenhista e o olho da coisa, que se dirigem mutuamente, tornando-se ao mesmo tempo agentes e pacientes dessa construção. Desenhar, assim, é demonstrar o interesse pelo percebido, voltar-se para ele com olhar concentrado, enfim, "é ter atenção aos traços do mundo" (Chuí; Tiburi, 2010: 63).

O desenhista produz, através dos mais diversos meios, evidências materiais dessa operação, deixa seus vestígios, sua memória. Contudo, cabe pensar que desenhar não se trata de experiência exclusiva dos que traçam, riscam, marcam, contornam, delineiam, enfim, figuram sobre certo suporte. Desenhar abrange todos aqueles que enxergam, que respondem à excitação do mundo visível, podendo ser interpretado no solo da vida intersubjetiva, aquela em que todo humano se reconhece como participante de um horizonte comum. Segundo 
Merleau-Ponty, uma intersubjetividade possível, posto que, pela vida corporal ${ }^{8}$, compartilhase a tradição primeira da percepção.

Luigi Pareyson oferece uma teoria que se harmoniza com esse ponto de vista ${ }^{9}$. Reconhece que a arte

(...) revela, frequentemente, um sentido das coisas e faz com que um particular fale de modo novo e inesperado, ensina uma nova maneira de olhar e ver a realidade; e estes olhares são reveladores, sobretudo porque são construtivos (Pareyson, 1997: 25).

Esse caráter construtivo do olhar não se verifica na arte fora do fazer, mas pela atividade artística, qualificada por Pareyson como formatividade. Trata-se de uma concepção dinâmica do formar, na qual execução e inventividade afetam-se mutuamente, e enquanto se executa, cria-se o "por fazer e o modo de fazer" (Ibid: 26). A espiritualidade do sujeito envolvido na atividade formativa só pode estar presente, então, como "energia formante" ou, aproximando Pareyson de Merleau-Ponty, pelo agir do Espírito Selvagem. E nessa perspectiva, como descrever o agir pelo desenho?

Cabe observar que o artista que desenha não exprime desenhos que já possui em mente, mas se situa em um campo desenhante, age e é agido por uma espécie de formatividade pelo desenho. "Traço. É neste lugar que cabe propor o problema do desenho como chão, como início e como fundamento" (Chuí; Tiburi, op. cit.: 79). Traço é sinônimo de risco ou linha, que em desenho adquire caráter de demarcação de contorno ou fronteira, delineamento ou corte, intervenção em algo que demarca e marca. Indicam percursos, direções, sentidos. É preenchimento e fenda, contato e separação, intervenção no indiferenciado que faz a diferença. O traço é a cicatriz da experiência do visível, sua memória.

Enquanto traça, o artista executa e inventa, assistindo a própria execução e invenção, acompanhando o traçado. Necessita ser espectador de sua própria experiência. Essa atitude é própria do corpo reflexivo, capaz de olhar e ser olhado. Olhar-se enquanto olha. Por essa via da reflexividade, característica do corpo-próprio e teorizada por Merleau-Ponty, o sujeito pode distinguir-se do outro, daquilo que não é. Assim, a experiência da visibilidade opera "a cisão que separa dentro de nós o que vemos daquilo que nos olha" (Didi-Huberman, 1998:

\footnotetext{
${ }^{8}$ Atual, operante, vidente e reflexivo, são algumas maneiras como Merleau-Ponty qualifica esse corpo humano, que não é um corpo em geral, mas o que "eu" vivo, no aqui e no agora. Ver "O olho e o espírito".

${ }^{9}$ Segundo o próprio autor essa concepção guarda afinidades com outros pensamentos modernos, dentre os quais destaca a estética francesa e a psicologia da forma.
} 
29). Por esse motivo, o traço, ação do desenho, evidencia esse corte que revela o mundo. A experiência do desenho é reflexão sobre ver, visão refletida.

Tal experiência se evidencia na poética de Amador Perez, ao problematizar o trabalho visual que subsiste e reinventa-se nas imagens retiradas da cultura visual, como nos redesenhos a partir de Gioventù, de Eliseu Visconti (1866-1944) ${ }^{10}$.

Motivado pela "oportunidade para problemas perpértuos e precisos" oferecidos pelo desenho, esse artista se vê convocado à tarefa de interrogar o território que o desenho circunscreve e não pode fazê-lo a não ser pelo exercício, perseguindo e atualizando constantemente os fundamentos do seu agir. Mas ao repetir indefinidamente o gesto primeiro de traçar, faz-se necessário reinventar os modos de tematizá-lo. É preciso que pela invenção se construam os modos de seu aparecer e que ele traga consigo um mundo dado a visualização: o mundo do artista que também é o mundo do desenho e o da cultura visual revisitados pelo artista através das coleções.

Na coleção originada em Gioventù (Fig.1) ${ }^{11}$ observa-se o insistente e renovado interesse do artista pela corporificação das imagens, pelos modos como encarnam, seja nas reproduções, seja nos originais.

\footnotetext{
${ }^{10}$ Gioventù (1898, óleo sobre tela, 65 x $49 \mathrm{~cm}$ ) foi realizada quando artistas brasileiros se empenhavam pela modernização da arte nacional, transitando entre movimentos como Realismo e Impressionismo, com versatilidade que se realiza em Eliseu Visconti, de modo exemplar. Esta obra simbolista conquistou a adesão de Amador Perez desde que a viu pela primeira vez, no Museu Nacional de Belas Artes do Rio de Janeiro, quando ainda estava na adolescência.
} 


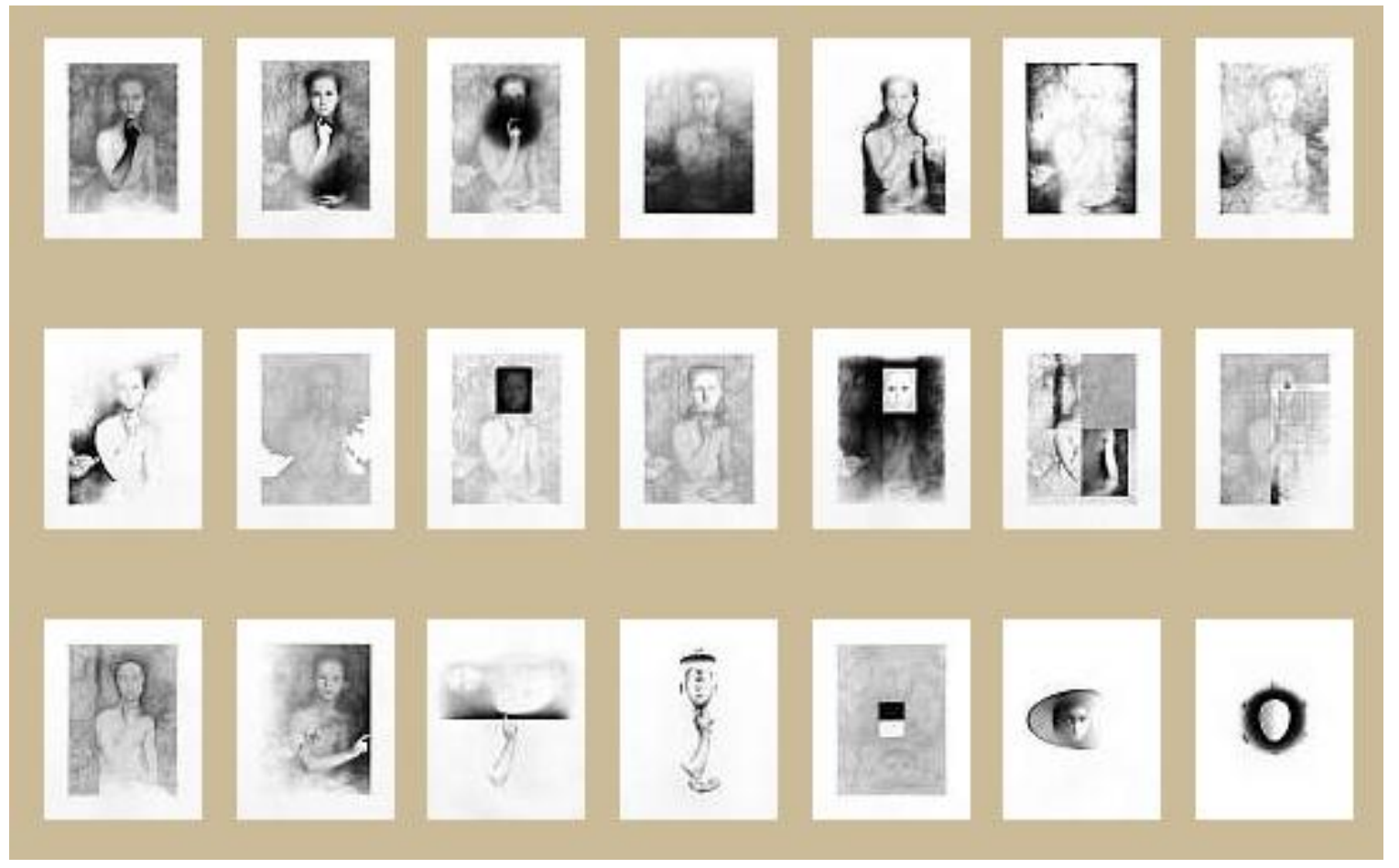

Fig. 1. Amador Perez. Conjunto de vinte e um desenhos da coleção composta por sessenta e três desenhos a partir de Gioventù, de Eliseu Visconti . Grafite, 1996-98. Disponível em http://www.amadorperez.com/por_fram.htm

A técnica refinada ou virtuosismo ${ }^{12}$ presentes em seus desenhos, que podem ser percebidos, prematuramente, como exaltação da semelhança com o real, da representação fidedigna da aparência das coisas, servem-lhe de pretexto para investigar a aparência das imagens. É o modo com que elas podem aparecer - desenhadas, pintadas, gravadas, fotografadas, impressas - enfim, que Amador Perez espera exaltar quando opera com maestria as convenções artísticas que sobrevivem nas reproduções. A transitividade da imagem em diversas encarnações, da gravura ao desenho, da pintura ao desenho, da fotografia ao desenho lhe interessam.

As motivações do artista, ao manipular as imagens da arte, verificam-se num campo bastante pessoal, não sendo possível justificá-las a partir de um programa de arte determinado. Ancorada em escolhas afetivas e nos marcos iniciáticos que retrocedem à infância e à formação edificada no cenário artístico-cultural dos anos de 1970 e 1980, a experiência desenhante de Amador Perez vem enriquecer o amplo espectro de poéticas particulares

\footnotetext{
${ }^{11}$ Composta de 63 desenhos sem títulos, em grafite e lápis de cor sobre papel, realizados entre 1996 e 1998 , a partir de um postal de 18,3 cm x 13,3 cm. Os desenhos realizados por Amador Perez apresentam as mesmas dimensões da reprodução utilizada como referência.

12 Cocchiarale (1992) observa que a "desconfiada reserva" ou "adesão irrestrita" ao virtuosismo em Amador podem dificultar a compreensão de sua obra.
} 
nascentes sobre o território movediço das vivências contemporâneas, Alquimia e transmutação. Assim, Cardoso (2003) refere-se ao processo criativo de Amador Perez, cuja chave se encontra, originalmente, nos desenhos. As interferências gráficas sobre o suporte, em suas variações cinzentas, que tiram partido do diálogo entre a substância escura do carbono e a alvura do papel, dão outra corporeidade ao tema apropriado pelo artista. A Gioventù pintada de Eliseu Visconti, já rematerializada e disseminada através de outras técnicas de reprodutibilidade, como a fotografia, em livros, postais, revistas, rematerializa-se mais uma vez nos seus desenhos, adquirindo não só outro aspecto, mas outros sentidos. Produzem-se outras dimensões sensíveis, outro estado da imagem, cuja singularidade encontrada no redesenho assume qualidade de original. Trata-se de uma nova realidade da imagem, experimentada tanto pelo artista que a executa pelo fazer quanto pelo espectador que a executa pela interpretação.

Além de operar a transmutação ou transubstanciação da imagem, o desenho de Amador Perez - preciso, elaborado, meticuloso e demorado - adquire um caráter perscrutinador. Esse caráter pode ser entendido como próprio do desenho de observação que se faz ferramenta de investigação da imagem referencial. Amador Perez necessita observá-la, proceder sua inquisição, sendo capaz de traduzir, através de outro recurso material e com fidelidade, suas qualidades visuais para, uma vez estabelecida tamanha intimidade com a ordem dada, reinventá-la. Seu trabalho visual penetra as camadas da imagem apropriada, revelando meandros, intencionalidades, possibilidades, recusas. Restringindo o meio ao mínimo pigmento preto sobre papel -, prima por extrair da imagem o máximo, sua complexidade. Com o grafite, o artista acessa a imagem como um cirurgião ${ }^{13}$. Ele abre a imagem, indo à sua interioridade e mesmo ao seu avesso, para transformá-la não só a partir de si mesma e das repercussões em seu imaginário, mas das possibilidades expressivas inerentes ao material que selecionou para sua empreitada.

Assim, os desenhos deixam de ser espelhos de Gioventù para se tornarem espelhos da transmutação operada em seu trabalho visual e artístico. É isso que é posto em evidência, ainda que a imagem seminal resista sob as formas transfiguradas em outra realidade (Fig. $2 \mathrm{e}$ $3)$.

13 "Eu afino, afino, afino, para que o grafite funcione como um bisturi. Uma tentativa que eu já sei que é impossível, de entender a imagem, compreender a relação que eu tenho com essa imagem em todas as instâncias.

Iluminuras, Porto Alegre, v. 15, n. 35, p. 180-197, jan./jul. 2014 


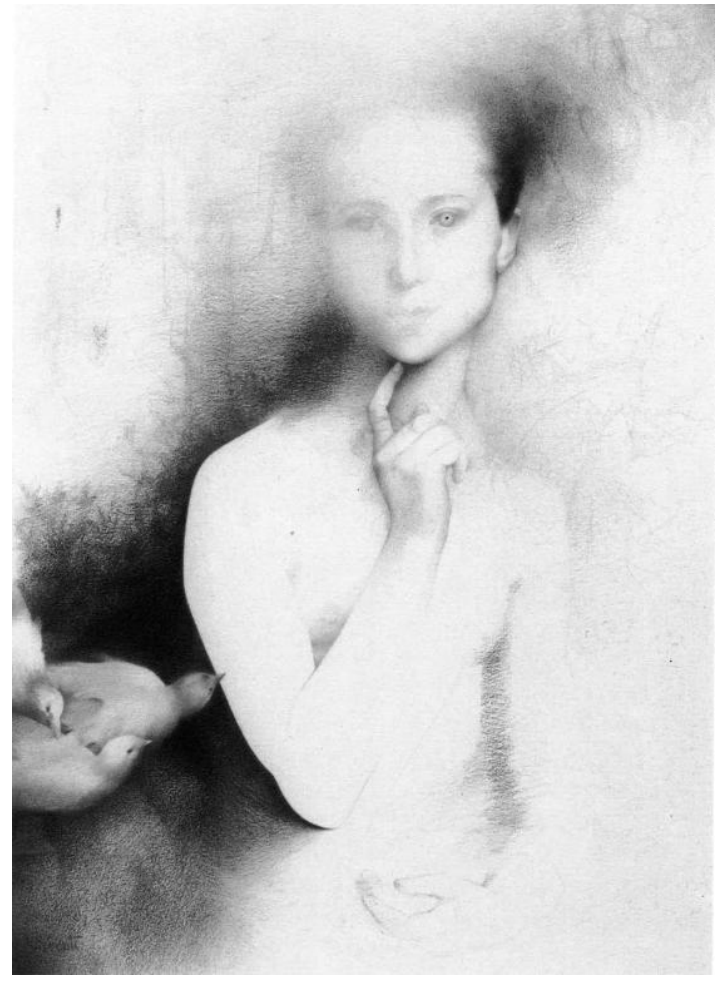

Fig. 2. Amador Perez. Sem título. Grafite, 18 x 13 cm, 1996-98. Foto: Coleção do Artista, 1999.

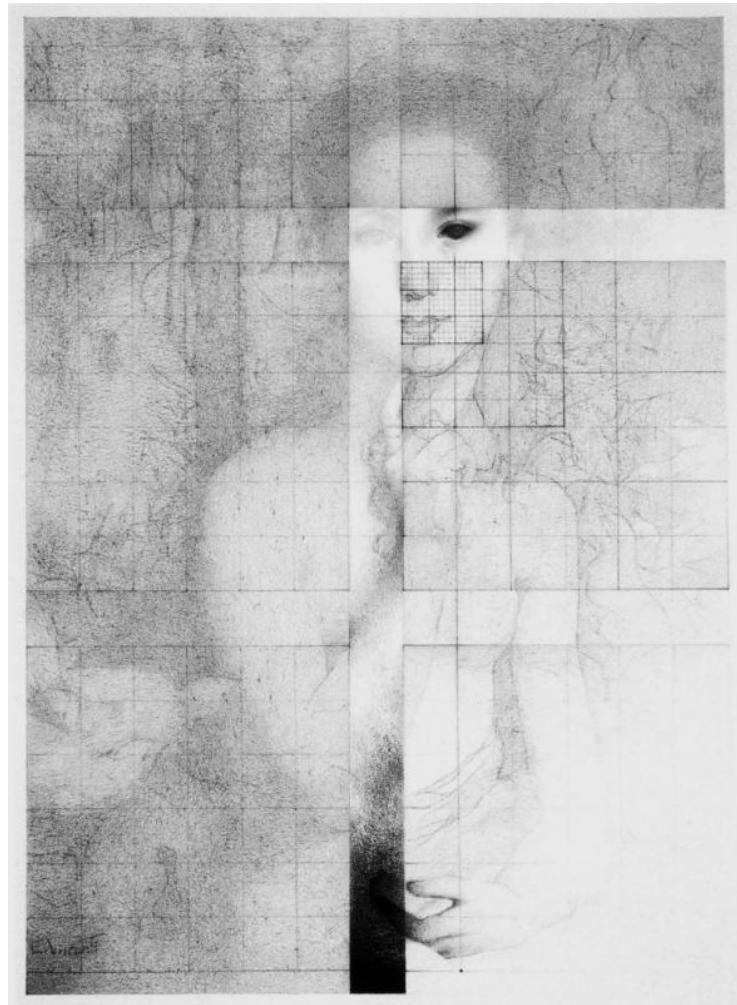

Fig. 3. Amador Perez. Sem título. Grafite, 18 x 13 cm, 1996-98. Foto: Coleção do Artista, 1999.

Começando na instância afetiva, chegando à instância histórica da imagem.” (PEREZ, Amador. Depoimento à

Iluminuras, Porto Alegre, v. 15, n. 35, p. 180-197, jan./jul. 2014 
A escolha do meio expressivo usado pelo artista não é descomprometida ou vã. Pode indicar a convicção de que o desenho é capaz de fazer emergir do papel o cerne da imagem, não como correspondência ao modelo, mas aquela que se anuncia como possibilidade, a ser manipulada e ressignificada pelo desenhista. Lembra Merleau-Ponty que

A palavra imagem tem má fama porque se creditou irrefletidamente que um desenho era um decalque, uma cópia, uma segunda coisa, e a imagem mental um desenho desse gênero no nosso bazar privado. Mas se, com efeito, ela não é nada de semelhante, o desenho e o quadro não pertencem, tal como ela, ao em si. Eles são o interior do exterior e o exterior do interior, que a duplicidade do sentir torna possível, e sem os quais jamais se compreenderá a quasi-presença e a visibilidade imanente que constituem todo o problema do imaginário. (2004b: 24)

Essa "quasi-presença" da Gioventù viscontiana, sua visibilidade imanente, inseparável do desenho pelo qual ganha existência, é perseguida por Amador Perez. Em sua operação desenhante, o artista talha e retalha o papel com grafite, cercando, sucessivas vezes, a imagem que o branco oculta, aparando-a e revelando-a, como quem rodeia um bloco de pedra e, a cada talho, fricção ou polimento, provoca sua aparição.

Baralhando o visível numa manipulação rigorosa, Amador Perez disseca a rede de sentidos tecida por Visconti, para fiá-la novamente, revelando vias e desvios do trabalho visual e inventando outros. Conserva qualidades icônicas da obra apropriada, mas, ao refazer relações, oferece-nos um evento singular em cada desenho. Através de reenquadramentos, cortes, adições, deslocamentos, fraturas ou nesgas, exalta o processo inventivo do sistema de equivalências que a experiência artística precisa lançar mão. Apagar, suprimir, esmaecer são outras operações realizadas. Às vezes, Amador Perez reforça silhuetas de partes do corpo, ressalta os contornos e dissolve o recheio, a matéria, como se afirmasse a presença pela ausência, a materialidade pela desmaterialização, ora da linha, ora da mancha. Restam bordas, contornos, pistas de um preenchimento. Noutras, destaca certas partes pela atribuição de matéria, de densidade, pela mancha negra, pela pigmentação concentrada do grafite. Amador Perez assinala, então, a impermanência dos lugares, que se reinscrevem, na alternância entre aparecer e desaparecer, ocupar e desocupar, acender e apagar. Aciona esse espaço de significação entre as coisas, o vazio entre-corpos, para mostrar que ele existe, prepara e sustenta a percepção e significação da imagem. Com sucessivas reinvestidas à obra e transmutações dos seus elementos, o artista convida e espectador a assistir à atuação do Espírito Selvagem sobre a imagem. Em cada investida, a imagem é reinaugurada em sua 
formatividade. Em um dos desenhos (Fig. 4), os elementos faciais da jovem orbitam em torno de uma forma oval, sem face, na iminência de fazerem sentido, de fecundá-la, sugerindo uma incubadora de sentidos, o trabalho na fonte bruta que sustém a imagem.

Para Frederico Morais, "o fato de que seus desenhos geralmente compõem séries fechadas define sua atividade criativa como atos reflexivos, como narrativas conceituais" (Morais, 1999: 11). A narrativa se dá pela articulação entre os desenhos, cada um evocando aspectos de uma reflexão continuada. Assim, os 63 desenhos oferecem aos espectadores e ao seu próprio autor (o primeiro espectador, ainda durante o fazer artístico) procedimentos interpretativos da imagem criada por Eliseu Visconti. Os diálogos possíveis travados na coleção desdobram-se na passagem de um desenho a outro, na passagem de um artista a outro (Visconti e Perez). Os intervalos entre os desenhos, aquilo que os separa, as pausas ou vírgulas na narrativa são tão importantes quanto cada desenho em si. São como interseções ou pontos de extravasamento, espaços de suspeita sobre aquilo que em cada desenho falta ou excede.

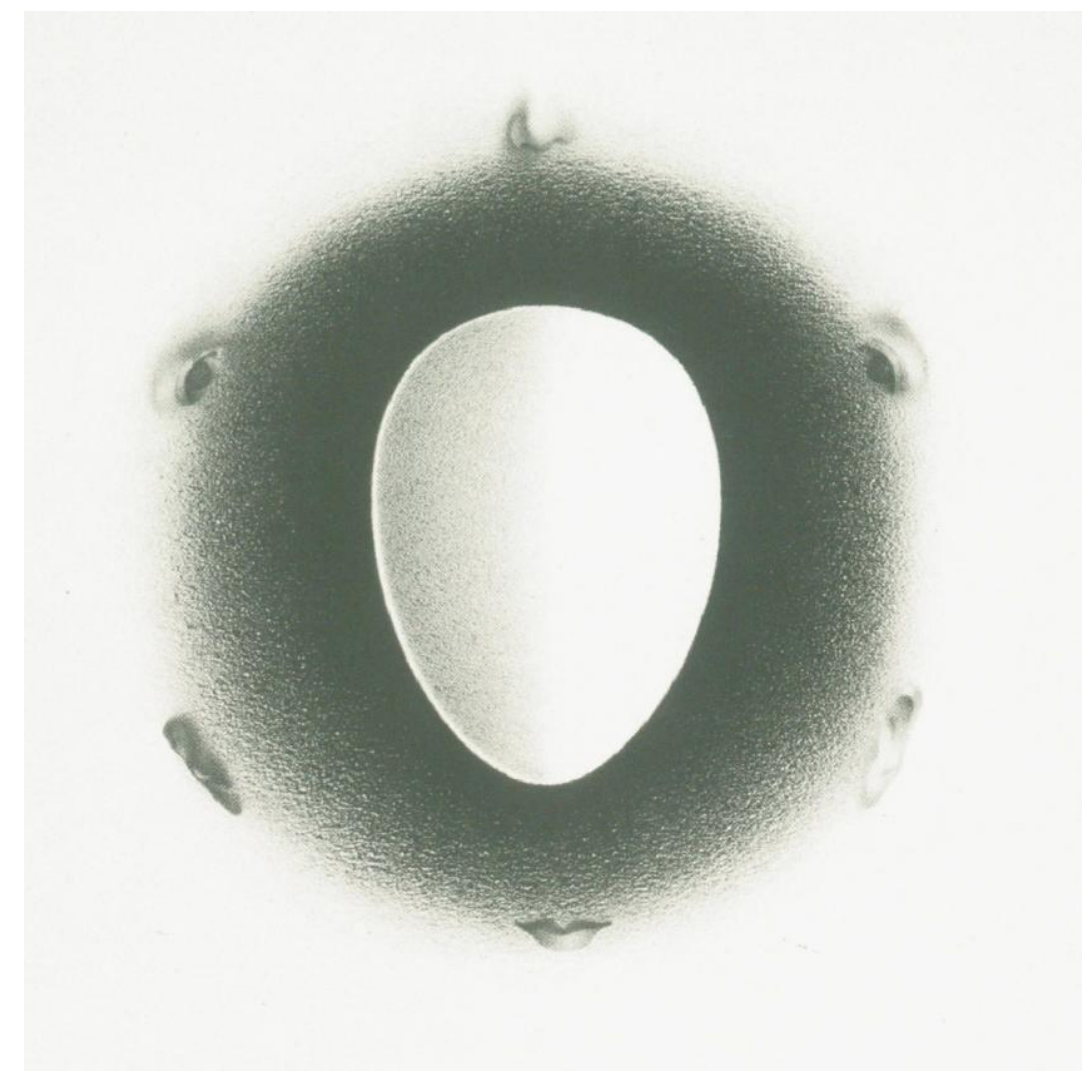

Fig. 4. Amador Perez. Sem título. Grafite, desenho a partir de Gioventú, de Eliseu Visconti, 13 x 13cm, 1996-98. Foto: Coleção do Artista, 1996-98. 
Em um texto dedicado à Gioventù, de Visconti, Rafael Cardoso faz um agradecimento a Amador Perez, pelo fato de que a coleção de desenhos lhe deu "olhos para enxergar realmente essa obra" (2008: 131). De que modo?

Cardoso problematiza como os conteúdos simbólicos na obra de Visconti - alegoria da juventude, realizada no contexto francês de fim de século, favorável às experiências simbolistas - materializam-se, ganham visibilidade. Para tanto, esmiúça a camada pictórica e os efeitos produzidos pelos meios de que o artista dispunha, em busca das significações ligadas ao tema. Cardoso conclui que os conteúdos simbólicos veiculados na tela não estão apenas relacionados às figurações existentes: moça na puberdade, pombas brancas, natureza ao fundo. Para ele, há recursos empregados com maior participação na inteligibilidade da obra, que são "a fatura, o modo de pintar" (Ibid: 128). As formas figuradas no quadro, sozinhas, não seriam capazes de sustentar seu simbolismo. Por isso Visconti apela para um cuidadoso tratamento da camada pictórica, valendo-se de áreas estratégicas em variações de velatura, transparência, nitidez ou desfoque, ressaltando ora a carnalidade dos elementos, ora sua imaterialidade. É o caso das pombas, que aparecem como seres quase etéreos cruzando o caminho da moça imperturbável. Esta, por sua vez, tem alguns pontos do corpo, como os lábios e o braço, mais nítidos, enquanto todo o resto do corpo parece dissolver-se numa frágil materialidade. Nada está ancorado nas leis naturais, nem pombas e nem moça. O que se realiza é a ideia de impermanência da carne, da pureza, da ingenuidade, evocada na fatura diluída e vaporosa.

Os redesenhos de Amador Perez dão "olhos para enxergar realmente essa obra", à medida que iluminam esses aspectos. Com seus jogos de claro/escuro, traço/mancha, opacidade/transparência, contornos delimitados/dissolvidos, o desenhista indaga e salienta a fatura de Visconti, levando a notar um trabalho visual que antes poderia passar despercebido (Fig. 5).

Desse modo, o seu trabalho de criação na imagem de referência revela-se, também trabalho interpretativo, uma espécie de exercício de crítica da arte, aspecto já observado por Daniel Piza (1991), que afirmou que "os desenhos de Amador são a melhor forma possível de crítica de arte". Vale ressaltar que a crítica de arte não se esgota na linguagem verbal, embora esta seja a sua forma usual de realização, podendo se constituir de outros processos de interpretação e transmissão (Argan, 2004: 21). E toda interpretação requer execução, segundo Pareyson, que a compreende no contexto da experiência visual, como operação semelhante a do músico, orientado pela partitura musical, ou a do ator, frente ao texto dramático. Diante da 
obra visual, o fruidor (ou intérprete, que pode ou não encarnar a figura do crítico) é provocado a executá-la pelo trabalho visual que ela lhe exige para fazê-la viver, torná-la presente, retirando-a da imobilidade. Sem a visualização, modo de executar a obra visual e iluminá-la, a obra se mantém na escuridão. De qualquer modo, trata-se de perseguir os sinais de visualização "querida pela própria obra” (Pareyson, 1997: 211). A conclusão de Pareyson é precisa: "a obra exige execução porque ela nasce executada"

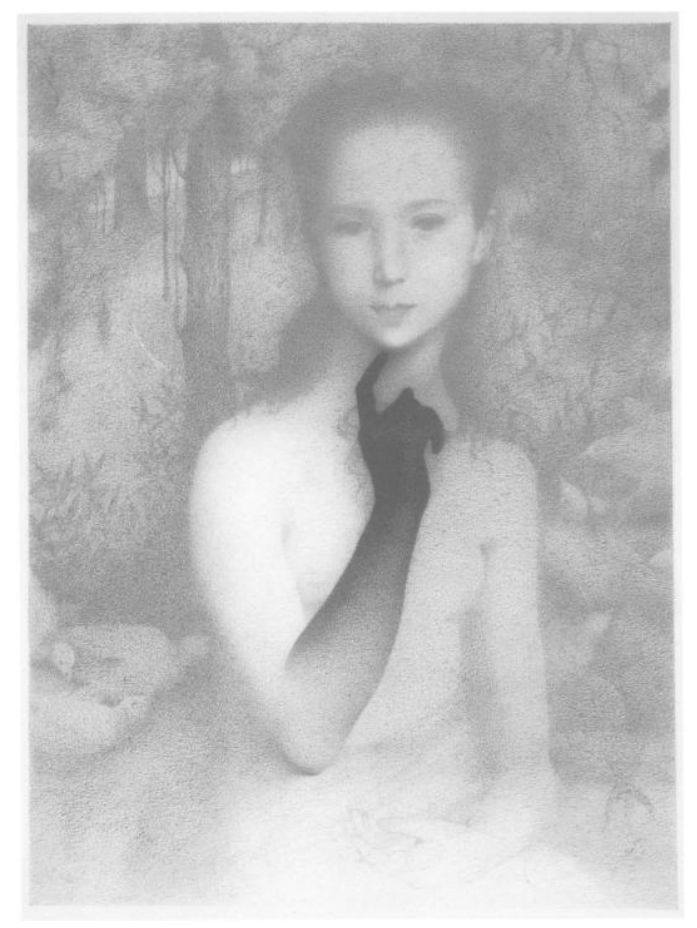

Fig. 5. Amador Perez. Sem título. Grafite, 18 x 13 cm, 1996-98. Foto: Coleção do Artista, 1999.

Mikel Dufrenne oferece compreensão semelhante do processo interpretativo nas artes visuais. Quando discorre a respeito do parentesco baseado na experiência criadora que aproxima as artes das palavras às artes da visão, Dufrenne (1981: 124) aponta a diferença da arte visual: "faz ver, ao fazer isso ela mostra, ela não diz".

Desse modo, o que a imagem espera, ao se mostrar, é ser olhada. Ser olhada, para ser compreendida. Compreensão esta, entendida aqui como faculdade de perceber, que jamais se esgota em uma única interpretação, contudo se reinaugura e exercita nas visualizações possibilitadas no encontro com a imagem.

Frente às imagens que o provocam, especialmente Gioventù, Amador Perez se vê convocado a executá-las pelos meios próprios da arte - desenhos com valor de intérpretes - 
capazes de enriquecer, através de execuções singulares, nossa própria interpretação da arte do passado e do imaginário que ela detém. Assim, desfiando imagens prévias e fiando outras, evidencia o trabalho visual requerido pela experiência artística, que esgarça as tramas de um mundo cultivado, para atingir sua origem no mundo percebido e devolvê-las, de algum modo, refeitas.

Assim, tendo em vista o horizonte das reflexões apresentadas nesse artigo, motivadas e orientadas, também, pelas reflexões desenhadas de Amador Perez, procurou-se chamar a atenção para a freqüentação da visualidade através do olhar, contato primeiro com a imagem, momento em que o logos estético precede e funda o logos cultural. Vale ressaltar que as perspectivas teóricas, históricas e críticas da arte podem ser beneficiadas ao serem reafirmados os laços com este saber fundador que as antecede e as ampara. A experiência da visualidade e o desenho de Amador Perez ensinam que toda oportunidade de reflexão sobre arte e cultura visuais também se apresenta como "uma oportunidade para problemas perpétuos e precisos" que exigem o engajamento do olhar.

\section{Referências}

ALMENDRA, Ludmila Vargas. Experiência do desenho: um estudo sobre poéticas desenhantes e Amador Perez. Rio de Janeiro, 2013. Tese (Doutorado em História e Critica de Arte). Programa de Pós-graduação em Artes Visuais da Universidade Federal do Rio de Janeiro, Rio de Janeiro, 2013.

AMADOR Perez - Artista Plástico. Disponível em: 〈http://www.amadorperez.com〉. Consultado em: fev. 2014

ARGAN, G. C.; FAGIOLO, M. Guia de História da Arte. Lisboa: Editorial Estampa, 1992.

ARGAN, G. C. "O valor crítico da 'gravura de tradução". In: ARGAN, G. C. Imagem e persuasão: Ensaios sobre o barroco. São Paulo: Companhia das Letras, 2004.

CARDOSO, Rafael. "Alquimia da imagem". In: PEREZ. Amador. A arte da impressão (catálogo). Rio de Janeiro: UERJ, 2003.

. A arte brasileira em 25 quadros (1790-1930). Rio de Janeiro: Record, 2008.

CHAUI, Marilena. Experiência do Pensamento: ensaios sobre a obra de Merleau-Ponty. São Paulo: Maryins Fontes, 2002.

DIDI-HUBERMAN, Georges. O que vemos, o que nos olha. São Paulo: Editora 34, 1998.

2013.

.Diante da imagem: questão colocada aos fins de uma história da arte. São Paulo: editora 34,

DUFRENNE, Mikel. Estética e Filosofia. São Paulo: Editora Perspectiva, 1981.

Iluminuras, Porto Alegre, v. 15, n. 35, p. 180-197, jan./jul. 2014 
MATTHEWS, Eric. Compreender Merleau-Ponty. Petrópolis, RJ: Vozes, 2011.

MERLAU-PONTY, Maurice. Fenomenologia da percepção. Rio de Janeiro: Freitas Bastos, 1971. Conversas-1948. São Paulo: Martins Fontes, 2004a.

O olho e o espírito. Lisboa: Vega, 2004b.

MORAIS, Frederico. “Amar o desenho". In: PEREZ, AMADOR. Coleção do Artista (Artist's Collection). Rio de Janeiro: Editora Fraiha, 1999.

PAREYSON, Luigi. Os problemas da estética. São Paulo: Martins Fontes, 1997.

PASCAL, Dupont. Vocabulário de Merleau-Ponty. São Paulo: Martins Fontes, 2010.

PEREZ, AMADOR. Coleção do Artista (Artist's Collection). Rio de Janeiro: Editora Fraiha, 1999 (Textos de Fernando Cocchiarale e de Frederico Morais).

PIZA, Daniel. Desenho: imagens e espaços. Jornal Estado de São Paulo, 1991. Disponível em: $<$ http://www.amadorperez.com>. Consultado em: fev. 2014. 